\title{
Hacia una teoría pragmática y psicoanalítica de porqué las palabras curan. La literalidad de la palabra y la eficacia simbólica en la metáfora
}

Toward a pragmatic and psychoanalytical theory on the
healing properties of words. The speech literality and the
symbolic efficacy in the metaphor

Mauricio Garcial

Resumen

El porqué las palabras curan sigue siendo el enigma mayor de las psicoterapias. Para profundizar su comprensión es necesario superar el abordaje lógico-semántico del discurso, según el cual la clave estaría en la producción de sentido, e introducir una visión pragmática para cernir la condición de acto de la palabra. Se comienza analizando el concepto de "Eficacia Simbólica", mostrando los aportes e impases que genera. Luego se reformula la cuestión de la eficacia desde la teoría psicoanalítica de la simbolización, introduciendo aportes de la filosofía analítica. Se concluye que la eficacia del diálogo terapéutico estriba en la literalidad de la palabra y no en sus sentidos segundos, pero a condición de que dicho diálogo haga emerger "promesas de sentido" nunca cumplidas plenamente.

Palabras clave: eficacia simbólica, simbolización, metáfora, cura psicoanalitica, cura por la palabra.

$1 \quad$ Psicoanalista (miembro de la Escuela Belga de Psicoanálisis), Psicólogo y Doctor en Psicología (U.C. de Lovaina). Profesor en la Universidad Facultés Universitaires Saint Louis, 43 Bvd. du Jardin Botanique, 1000 Bruselas, Bélgica. E-mail: garcia@fusl.ac.be 


\begin{abstract}
Why the speech cures, is still the major enigma of psychotherapies. For deepen in its comprehension, we must go further than the logic-semantic approach of discourse -which states that the key would rely on the production of sense and meaning- introducing a pragmatic standpoint to understand the speech like an act. This paper starts with a critical analysis of "Symbolic Efficacy", showing its advantages and its drawbacks. Afterwards, the question of efficacy is reformulated from the psychoanalytical framework, and some contributions from analytical philosophy. It is concluded that therapeutic dialog's efficacy comes from the literality of the discourse and not from its secondary meanings. Nevertheless, this efficacy needs the emerging from the dialog "meaning promises", never plentifully achieved.
\end{abstract}

Key words: symbolic efficacy, symbolization, metaphor, psychoanalytical cure, talking cure. 


\section{Introducción}

La cuestión de porqué las palabras curan sigue siendo el enigma mayor de la clínica psicoanalítica y de las psicoterapias en general. ¿Cuál es la operatoria a través de la cual, hablando y dialogando, la palabra actúa sobre alguien al punto de suscitar su mejoría? Ya en 1935, Stefan Zweig formulaba muy bien el problema. Diferenció el método de la medicina científica y el método psicológico. El primero, según Zweig, consideraría al enfermo como un objeto, en tanto le impone una pasividad absoluta al paciente quien no tendría nada que decir ni demandar, solo seguir las prescripciones del médico. El segundo, situaría al paciente como sujeto, en tanto exige de él una gran actividad de sustentador de la cura.

El único, el verdadero remedio de todas las curas psíquicas, es ese llamado al paciente que lo implica en reunir todas sus fuerzas morales y concentrarlas en un haz de voluntad para oponerlas a la enfermedad. La mayoría del tiempo la asistencia de los que curan se reduce a las palabras; pero quien conoce los milagros operados por el logos, el verbo creador, esa vibración mágica de los labios en el vacío que ha construido y destruido mundos innombrables, no se extrañará de ver, en el arte de curar como en todos los otros dominios, maravillas realizadas únicamente por las palabras. No le extrañará ver que en organismos a veces completamente destrozados se reconstituye la salud solamente a través del espíritu, por el medio de la palabra y la mirada. Estas curas admirables no son en realidad ni raras ni milagrosas: reflejan vagamente una ley aún secreta para nosotros y que en tiempos venideros tal vez se profundizará (Zweig, 1935, p. XIX).

La investigación empírica en psicoterapia, pese a haber ido más allá de la investigación de resultados para concentrarse en el proceso, no ha generado, hasta donde se conoce, paradigmas que permitan investigar este problema. Probablemente una de las razones de esto es que se ha asumido casi como de suyo que la eficacia del discurso (de las narrativas, del relato, etc.) en psicoterapia reposa en su capacidad de producir sentido, 
significación o comprensión de los síntomas, dolores, conflictos, problemas o malestares que aquejan al paciente. Y no es simple objetivar la producción de sentido, el que se resiste a toda generalización o matematización. Con todo, reflexiones teóricas en distintas tradiciones de la psicoterapia se han interesado crecientemente en el punto de vista pragmático sobre el lenguaje para generar modelos de lo que opera en la cura.

En este trabajo se intentará explorar el problema en y desde el psicoanálisis, privilegiando la discusión en torno al concepto de "simbolización", pues es este uno de los vértices para pensar la eficacia "simbólica" de la palabra. Se propone que pensar exclusiva o dominantemente la eficacia en términos de sentido impide dar cuenta del problema, por lo que se hace necesario introducir una perspectiva pragmática para ceñir más coherentemente la operatoria de la eficacia terapéutica. La hipótesis subyacente es que hay algo en la tradición misma del psicoanálisis, una perspectiva lógico-semántica, que impide dar cuenta de la palabra como acto de la pragmática del discurso. De los innumerables elementos y momentos del pensamiento psicoanalítico que se podrían explorar sobre este problema, se ha elegido centrarse primero en cómo Lévi-Strauss (1958) renovó las coordenadas del problema con su texto sobre la eficacia simbólica. Desde una lectura de los impasses en que cae Lévi-Strauss, se muestra cómo estos también están presentes en el psicoanálisis desde Freud. Luego se exploran algunas pistas sobre el punto de vista pragmático, concentrándose en las teorías de la metáfora que ha promovido la filosofía analítica en tensión con la perspectiva psicoanalítica, particularmente la corriente francesa.

\section{La eficacia simbólica}

Este es un texto mayor de la antropología estructural, que ha tenido un impacto muy marcado en la manera en que el psicoanálisis francés piensa la cuestión de cómo las palabras curan, particularmente en la tradición lacaniana. Sin embargo, hay una paradoja en el texto, la cual se espera mostrar, puesto que Lévi-Strauss logra dar cuenta sobre todo del carácter simbólico de la cura chamánica más que de los resortes de su eficacia. 
La descripción de una cura chamánica entre los Cunas conduce a Lévi-Strauss a preguntarse cómo el discurso del chamán -sus narraciones, sus gestos, la puesta en escena- logra hacer parir a una mujer que, en medio de un gran sufrimiento, no podía hacerlo.

Su primera proposición es que la cura sería un proceso que hace "pensable" una situación dada, de tal suerte que los dolores se hacen aceptables y tolerables para el espíritu de esta mujer. Y agrega que: “... la mitología del chamán no corresponda a una verdad objetiva no tiene importancia: la enferma cree y es miembro de una sociedad que cree" (LéviStrauss, 1958, p. 226). El problema no consiste entonces en determinar la objetividad ni la verdad del discurso sino su capacidad de actuar y operar efectos. Después de decir que consiste en hacer "pensable" algo, LéviStrauss plantea el problema pragmático: que el discurso haga pensable algo (el sufrimiento), ¿da cuenta de por qué actúa y es eficaz? No, puesto que la enferma "habiendo comprendido no solo se resigna: se cura. Y nada parecido ocurre entre nuestros enfermos cuando se les ha explicado la causa de sus desórdenes invocando secreciones, microbios o virus" (1958, p. 226). Por lo tanto, "hacer pensable", explicar o poner orden no bastan para que la cura tenga lugar en tanto evento pragmático.

El primer intento de comprender esta diferencia será decir que el lenguaje de los microbios -el discurso científico causalista- es "exterior” al espíritu de la enferma, mientras que aquél del chamán es "interior" a ese mismo espíritu, consciente o inconsciente. Esta sugerencia es interesante; pero, ¿qué quiere decir eso de un lenguaje interior al espíritu? Lévi-Strauss no dice más, salvo que sería un lenguaje "en el cual se pueden formular estados informulados y de otro modo informulables" (1958, p. 226). Esto hace eco a algunos aforismos contemporáneos, como aquel según el cual un mito permite decir lo que no se podría decir de otra manera. Aunque todo esto es vago. En este punto de su reflexión, Lévi-Strauss concluye que "es el paso a la expresión verbal [...] lo que provoca el desbloqueo del proceso fisiológico" (1958, p.226), la cura. Pero justamente el problema era que esto no bastaba. La explicación del lenguaje científico también opera un pasaje hacia la expresión verbal y, sin embargo, no es eficaz en el sentido que le da a este concepto Lévi-Strauss. En tanto no logra precisar 
esta "interioridad” del lenguaje del chamán, reduce el problema al plano de la expresión verbal.

Se podría decir que la interioridad en cuestión puede ser formulada de dos modos: a) el lenguaje del chamán es un lenguaje cercano a lo sensible, no es una abstracción, como el lenguaje científico, lo que implica que el lenguaje eficaz es aquel que formula las cosas de manera cercana a lo vivido, a la experiencia; b) el lenguaje del chamán es un acto, comporta un vector pragmático que le da la "fuerza" -como decía Austin (1962) respecto al performativo- de una simbolización. Esta fuerza es interior a su discurso puesto que es indisociable de la enunciación misma. El chamán no evoca solamente el dolor, no solo lo expresa, sino que sus relatos actúan sobre la realidad del cuerpo de la enferma. Este vector pragmático es posibilitado por una institución social: chamán y paciente creen en el mito, y el chamán es alguien validado para proferir ciertos relatos y narraciones. Pero la institución opera como un contexto que solo el observador puede aislar. Para los actores de la cura, el contexto es interior a la enunciación. Esto quiere decir que la eficacia simbólica es simbólica porque está articulada al lenguaje, pero eficaz en tanto acción, fuerza pragmática, susceptible de transformar, mutar un estado dado. Esta es la razón por la que tiene interés acercar esta reflexión de Lévi-Strauss al problema de la simbolización en el psicoanálisis. Lévi-Strauss (1958) da cuenta sobre todo del carácter simbólico de la palabra y la gestualidad del chamán más que de su operatividad radical. Y sin embargo esta cuestión emerge sin cesar bajo su pluma.

Luego Lévi-Strauss compara chamanismo y psicoanálisis en varios puntos. Las dos prácticas intentarían traer conflictos y resistencias a la conciencia. La resolución no se produciría por un simple conocimiento o toma de conciencia de todos estos factores, sino a través de una "experiencia específica en cuyo curso los conflictos se realizan en un orden y en un plano que permite su libre desarrollo y conduce a su desanudamiento" (1958, p. 227). ¿Cuál es este plano? ¿Es acaso el sentido adquirido psíquicamente? ¿Es el hecho de la producción de significaciones? En buenas cuentas, ¿`se trata de un plano semántico o pragmático? Al parecer, los dos están mezclados, 
el primero permite el libre desarrollo (la gramática y la retórica inconsciente que permite la formación de metonimias, metáforas, la figurabilidad, etc.); y el segundo, el vector pragmático, permitiría el desanudamiento. En este sentido, la especificidad de la experiencia en cuestión reside en el hecho de que no es sólo significativa o expresiva (verbalmente), sino también "mutativa” (Strachey, 1934). La pragmática del discurso marcaría, de esta forma, la especificidad de esta experiencia.

Lévi-Strauss no ve las cosas así, prueba de ello es que acerca la especificidad de esta experiencia a la abreacción, como formulación de una situación no formulada. Pero, según el psicoanálisis, la abreacción no cambia mucho las cosas: alivia, pero sólo por un tiempo. No modifica el conflicto ni la posición del sujeto respecto al conflicto. Usando la terminología del propio Lévi-Strauss, diríamos que la abreacción permite el libre desarrollo, pero no el desanudamiento.

La dificultad para salir del formalismo y pensar la pragmática se hace notar también en otra manera que propone Lévi-Strauss de concebir la cura como funcionamiento ordenado. Escribe: "También allí [en el chamanismo], se trata de suscitar una experiencia, y, en la medida en que esta experiencia se organiza, mecanismos ubicados fuera del control del sujeto se regulan espontáneamente para llegar a funcionar ordenadamente" (1958, p.227). Tendríamos entonces que la narración del chamán ordena el sufrimiento, lo sitúa en un orden simbólico y, en tanto ordena, cura; pero también podríamos decir, legítimamente, que es porque transforma la posición del sujeto que ordena. ¿Por qué dar el primado a lo formal en detrimento de lo accional? ¿Por qué dar prioridad a lo semántico en la teoría y no a lo pragmático?

La comparación entre Chamanismo y Psicoanálisis va más lejos. El psicoanalista tendría un rol fundamentalmente de auditor, mientras que el chamán sería más activo, es orador. En psicoanálisis, "el paciente hace hablar al psicoanalista suponiéndole sentimientos e intenciones" (la transferencia), mientras que el chamán "habla por su enferma", suscitando en ella una identificación "a un chamán míticamente transpuesto" (LéviStrauss, 1958, p. 227). 
Otros factores estarían invertidos según Lévi-Strauss, pero, más allá de eso, ambas técnicas buscarían producir la experiencia de hacer vivir un mito al paciente. Mito individual (producido) en el psicoanálisis, mito social (recibido) en el chamanismo.

Luego Lévi-Strauss (1958) compara el chamanismo con una "variante de la cura tipo", en la cual la Sra. Sechehaye da cuenta de una cura con un esquizofrénico. Ella constata que su discurso, por muy simbólico que sea, no toca los complejos del enfermo. Realiza entonces actos, gestos, como tomar al paciente en sus brazos permitiendo el contacto de la mejilla de aquel con su seno. La carga simbólica de los actos los haría propicios para constituir un lenguaje -dice Lévi-Strauss- a través del cual la psicoanalista se comunica con su paciente y produce efectos de "desanudamiento" de los complejos. Interesa hacer notar que para Lévi-Strauss es el acto lo que puede devenir simbólico -lo que parece pertinente y fecundo para analizar muchos materiales y fenómenos- pero no concibe lo inverso, a saber, que los símbolos y los discursos son o pueden ser actos y que es en tal condición que son eficaces.

Casi al final de este texto, Lévi-Strauss deduce un axioma a partir de la esperanza freudiana de que algún día la concepción psicológica de las patologías debería desaparecer ante una concepción fisiológica o incluso bioquímica. El axioma consiste en plantear que habría una analogía estructural entre el nivel orgánico y lo psíquico inconsciente (el espíritu). Define entonces la eficacia simbólica como una "propiedad inductora" entre los niveles. En tanto estos serían análogos estructuralmente, "la eficacia simbólica consistiría precisamente en dicha propiedad inductora que poseerían, unas respecto de las otras, estructuras formalmente homólogas, pudiendo edificarse, con materiales diferentes, en los diferentes niveles del viviente: procesos orgánicos, psiquismo inconsciente, pensamiento reflexivo" (1958, p. 231). ¿Qué es lo que lo obliga a plantear esta analogía fuertemente discutible? Podría ser la dificultad de aprehender los elementos productores de la eficacia en el discurso mismo; el problema de poner en evidencia la dimensión de acto de la palabra lo obligaría a este rodeo. Es probable que sea esta misma limitación la que impulsa la esperanza naturalista de Freud. 
Pero Lévi-Strauss quiere ir más allá. Inmediatamente después de la definición citada, compara esta "propiedad inductora" con la metáfora poética y no con la conversión o la psicosomática, modelos que serían más propicios para operar como ilustración de la homología entre niveles. Dice: "la metáfora poética nos da un ejemplo familiar de ese proceso inductor: pero su uso corriente no le permite sobrepasar lo psíquico. Constatamos así el valor de la intuición de Rimbaud al decir que la metáfora puede también servir a cambiar el mundo" (1958, p. 231) y no solo a significarlo simbólicamente; está a un paso de abrir la cuestión de la pragmática de la metáfora, como lo ha hecho posteriormente Davidson (1993). Si no, ¿qué significaría una concepción de la metáfora que "sobrepasa lo psíquico"? Esta enigmática frase es una intuición de que en el "uso corriente" (pues es ahí donde la metáfora no sobrepasa lo psíquico), la metáfora es reducida a la semántica, a una manera original de significar el mundo y a sí mismo, vía "substitución significante". Para Rimbaud (citado en Lévi-Srauss, 1958) la metáfora puede inducir una transformación, efecto que sitúa en el corazón de la eficacia simbólica la cuestión de la pragmática del discurso y la dimensión accional de la palabra; lo que debería ocupar un lugar más central en la teoría analítica de la simbolización, sobrepasando el uso corriente que se hace de este concepto.

Habría muchos otros comentarios que hacer sobre este texto lleno de genialidad, particularmente la proposición de lo inconsciente como una forma vacía "tan extraña a las imágenes, como el estómago lo es a los alimentos que lo atraviesan” (Lévi-Strauss, 1958, p. 233) órgano, de una función específica que impone leyes estructurales a toda suerte de elementos (pulsiones, emociones, representaciones, recuerdos). Todas estas cuestiones capitales se alejarían del propósito de este trabajo. Lo que interesa es poner en evidencia que la aproximación formal y categorial, comandada por una posición lógico-semántica, impide a Lévi-Strauss dar cuenta de la especificidad de su objeto, al mismo tiempo que la hace emerger. Interrogarse sobre la eficacia de los símbolos, de la narración y del discurso, implica atender no tanto a su función como al mecanismo de su intervención. Teorizar la práctica no implica solamente comprender la estructura inconsciente de las representaciones que la determinan, sino 
hacer emerger los esquemas constitutivos de toda representación y, por lo tanto, implica cambiar el sentido mismo del término representación (Augé, 1979).

Interrogarse sobre la eficacia simbólica implica reconocer no solo la eficacia de los ritos, sino también aquella del discurso mismo. Estudiando las representaciones culturales del sufrimiento, como por ejemplo la cuestión de los males hechos por envidia o la enfermedad del susto, se puede llegar a pensar que no son solo representaciones significantes, portadoras de sentidos diversos, sino también acciones, inductores de transformaciones subjetivas para aquellos que las hacen circular culturalmente, y por esa vía muestran una fuerza pragmática (García, 2000, 2001). No solo representan el sufrimiento sino que lo simbolizan, operando transformaciones en la experiencia del sujeto y en su posición. Si no pensáramos que los mitos mismos son eficaces deberíamos esperar que desaparezcan al desaparecer los ritos, o quedar como residuos de una cultura que ya no está viva. Esta perspectiva es una trampa, pues los mitos persisten e insisten, portando una operatividad de la palabra. Es la sola razón que nos permite entender su retorno incesante.

El funcionalismo, que tal vez las ciencias humanas tiraron a la hoguera con demasiada premura, merece ser revisitado. Es cierto que el sentido no es la función, y que la lectura funcional de los mitos dice más sobre el contexto del mito que sobre el texto, como lo señalara Lévi-Strauss. Sin embargo, más allá de esta discusión, la aproximación de Malinowsky (1974) al lenguaje, prefiguró en cierto sentido la teoría del performativo de la filosofía analítica y la pragmática del discurso. Jakobson (1963) y Benveniste (1967) retienen aquello de la comunicación pática, concepto referido al hablar ordinario centrado en el contacto y libre de la presión de la función informativa. Pero Malinowsky (1974) va más lejos, he aquí algunas frases publicadas en su diario de campo y sistematizadas por Adam (1990):

- "El lenguaje es esencialmente un modo de actuar, y no de contar una historia, de divertir o instruir desde un punto de vista puramente intelectual".

- $\quad$ "La principal función del lenguaje no es expresar el pensamiento 
ni reproducir la actividad del espíritu, sino jugar un rol pragmático activo en el comportamiento humano”.

“...las palabras intercambiadas no tienen por función primera transmitir el pensamiento, sino unificar el trabajo y coordinar las actividades de las manos y el cuerpo. Las palabras participan en la acción y son acciones" (citado en Adam, 1990, p. 256).

Esta potencia pragmática, Malinowsky la observa sobre todo en las fórmulas mágicas, los enunciados de carácter sacramental, los exorcismos, los encantamientos, todas formas del habla que se acercan mucho al discurso del chamán cuya cura analiza Lévi-Strauss. El maestro del funcionalismo llega incluso a utilizar la expresión "acto de habla” o "acto de palabra”, prefigurando la noción de Searle (1987). Dice Malinowsky (1974) que para el indígena una fórmula mágica es "un acto de habla que permite liberar tal o cual fuerza particular - un acto que [...] ejerce una influencia muy potente sobre los fenómenos de la naturaleza y la conducta humana” (citado por Adam, 1990, p. 258).

¿Será que lo inquietante de pensar la pragmática es que nos acerca al pensamiento mágico? Como sea, esta perspectiva complejiza las cosas pues lo extralinguístico deviene inseparable de toda posibilidad de comprender el intercambio y el discurso social. Searle (1987), por ejemplo, insiste en las condiciones extralingüísticas que especifican los roles y las posiciones legítimas para los sujetos. Lo que Austin (1962) llama "condiciones de felicidad del performativo" - las condiciones donde funciona- son ante todo condiciones sociales. ${ }^{2}$

\section{Implicaciones para una teoría psicoanalitica de la simbolización}

Este rodeo, que en verdad ha sido un sumergirse en cómo Lévi-Strauss piensa la eficacia, tiene por finalidad interrogar una fuente fundamental en la reflexión psicoanalítica de cómo las palabras curan. Interesa extraer algunas implicaciones para la teoría de la simbolización.

2 Pierre Bordieu ha subrayado que la reflexión de Austin no puede cantonarse en la pura lingüística, pues se trata de una construcción del objeto "discurso" que requiere el concurso del conjunto de las ciencias humanas. La fuerza lingüística -como dice Bourdieu parafraseando a Austin- no queda definida por la puras competencias lingüísticas, “...y el peso de diferentes agentes depende de su capital simbólico..." (Bourdieu, 1982, p. 68). 
Para decirlo de una manera simple y dejando de lado muchas complejidades, se podría formular la siguiente proposición: el psicoanálisis ha mostrado que la palabra es eficaz. La antropología nos recuerda que la humanidad no esperó al psicoanálisis para producir discursos susceptibles de operar transformaciones sobre el alma y el cuerpo. Los grupos humanos se dotan de representaciones y discursos que operan un acto transformador, potencialmente capaz incluso de producir la cura. La palabra es eficaz, sin duda. El problema radica en la manera de pensar esta eficacia. Freud se ocupa de mostrar que el sueño y el síntoma tienen un sentido. Su posicionamiento primero frente a su objeto es el de un intérprete. Por ello, la articulación de su discurso teórico es comparable al de una gramática, una semántica y/o una sintáctica: se interesa en el sentido y en sus reglas de producción. La cuestión de cómo la palabra cura se plantea posteriormente en Freud. De hecho es una sorpresa que le es revelada por Anna O., quien llamará, a lo que hacían, talking cure (cura por la palabra). La cuestión de la operatividad del discurso es segunda en Freud, y algunas huellas de dicha secundariedad se hacen sentir en sus dificultades para poder pensar las producciones discursivas de la cultura (totemismo, mito, tragedia, etc.) como un acto eficaz y no solo como un sentido enmascarado, deformado, trucado. Su pensamiento está marcado de manera predominante por una perspectiva lógico-semántica. Y como la cuestión pragmática está presente de modo secundario, le es difícil imaginar que el discurso cultural pueda ser, por su enunciación y puesta en circulación, operante y eficaz.

Es probablemente por esto que el pensamiento psicoanalítico sobre el proceso de simbolización, pese a indicar que se trata de un proceso y no de una simple operación de lenguaje, sigue estando -a mi juicioparcialmente tomado por la perspectiva lógico-semántica. Esto impide, también, parcialmente, dar a la interpretación analítica su dimensión transformacional, describiéndola como un actuar pragmático que suscita pasajes y mutaciones. Es por ello que la simbolización parece ser un modelo útil para pensar la interpretación analítica en su eficacia. Si se está de acuerdo en que hacer consciente lo inconsciente no es lo que cura, 
habría que desarrollar más el vector pragmático para dar cuenta de aquello que para Freud venía "por añadidura".

No se trata de renunciar a todo lo que nos ha aportado la reflexión sobre el lenguaje. Sería caer en ese simplismo, tan de moda, que da todo por "superado". Para dar cuenta de una simbolización hay que hablar. Pero más aún, la simbolización como proceso humano se desarrolla en un ser hablante y por tanto moviliza toda la capacidad semiótica de un sujeto. Hay substitución, representación indirecta, significaciones, sentidos y sinsentidos, entendidos y malentendidos, hay todo lo que promueve la inscripción del humano en el lenguaje. El problema es que una vez que se ha entendido algo, después de la interpretación, no se ha dado cuenta necesariamente de las razones por las cuales el discurso y la narración son eficaces. ¿¿Será por esto que en psicoanálisis podemos “comprender” mucho más de lo que somos capaces de transformar? Tal vez la investigación analítica sobre las representaciones culturales (entre otros dominios) podrá algún día hacer contribuciones sustantivas al respecto. Lévi-Strauss ya había señalado esta pista:

La comparación con el psicoanálisis nos ha permitido esclarecer algunos aspectos de la cura chamánica. No está excluido que, inversamente, el estudio del chamanismo no esté llamado algún día a elucidar puntos que han quedado obscuros en la teoría de Freud (1958, p. 231).

Tal vez este análisis no ha avanzado más allá de lo hecho por Lévi-Strauss. No se ha propuesto una teoría de la simbolización que instale la palabra como acto. Más allá de afirmarlo no se profundiza en la teorización de este enigma. Se ha esquivado la cuestión del "acto analítico" (Lacan, 2001), con lo real que hay en él, siendo tal vez posible e imposible cernirlo con el discurso. Y en ese sentido, "si existe realmente un acto analítico" (Badiou, 2000, p. 252), ¿por qué es tan difícil hacer la teoría? Ocurre algo análogo a lo que se produce al momento de intentar explicar un poema o parafrasear una metáfora: se pierde lo esencial. La paráfrasis no tiene el mismo efecto y se instala casi como una resistencia a la poesía. 
Aperturas del problema pragmático al interior del Psicoanálisis

Octave Mannoni, autor lleno de sutileza y de una notable voluntad de claridad y rigor en su escritura, se pregunta por el estatuto de la metapsicología en el curso de un análisis. Narra brevemente un inicio de análisis, en que el paciente habla de una manera muy vacía, entregándole papeles médicos relativos a exámenes en vez de hablar. Sin saber si podría hacer algo por este sujeto, preguntándose incluso si el paciente no sería un débil mental, Mannoni no desespera y sigue escuchando. Al cabo de un mes, al final de una sesión particularmente plana, el paciente, con la mano en la manilla de la puerta, dice: "no voy a poder seguir viniendo". Esto no sorprende a Mannoni, quien le dice: “iPor fin! Es la primera vez que Ud. habla en su propio nombre” (Mannoni, 1987, p. 25-26). El paciente volvió a la sesión siguiente y se puso a hablar... en su propio nombre. Lo que siguió del análisis cambió la vida de ese paciente, al punto que llaman a Mannoni del hospital desde donde se lo derivaron para preguntarle la "receta milagrosa”.

La intervención de Mannoni no es una interpretación, pues no se trata del desencubrimiento de un sentido latente de "no voy a poder seguir viniendo". En el après coup Mannoni piensa que su intervención surge de un cierto saber, de una concepción teórica sobre el rol de la negación en la constitución del sujeto. Sin embargo, en lo vivo del diálogo no se produce esta reflexión teórica, de tal suerte que el ejemplo muestra que es con nuestro saber, sin referirnos a él, que encontramos las intervenciones en la clínica. Mannoni concluye que ante problemas como los que plantea el análisis, el analista busca una explicación metapsicológica, pero no la da en esos términos al paciente. Su tarea consiste en que la intervención esté al alcance del paciente, lo cual requiere sacarle su "aspecto teórico" (Mannoni, 1987, p. 29). De alguna manera, esta operación es lo que haría que el lenguaje del analista sea "interior" a la experiencia del paciente, como lo formulara Lévi-Strauss. Y es que justamente el análisis no es casi nunca una enseñanza, sino "una experiencia que modificará al sujeto que se implica en ella" (Mannoni, 1987, p.29). La finalidad del análisis "no 
es que el paciente aprenda algo, sino que sea cambiado" (1987, p. 29), sostiene Mannoni. Entre las dos figuras límite, aquella de un paciente que aprendió todo lo que podría aprender, sin haber avanzado mucho, y la de aquel otro que fue muy cambiado por su análisis sin poder decir qué es lo que aprendió, Mannoni prefiere la segunda. El analista interviene con y desde sus saberes, pero nada dice sobre ellos. Son su mapa y su brújula, le permiten orientarse y reaccionar analíticamente frente a los obstáculos con que tropieza el analizando.

Se desprende, entonces, que "lo que queda oscuro o mal conocido en el análisis no son sus métodos y sus prácticas, son sus resultados" (Mannoni, 1987, p. 29), en el sentido de que hace posible dichos resultados más allá de la descripción del método. Vemos cómo se formula la necesidad de una teoría pragmática de la intervención analítica, tarea frente a la cual la teoría de la transferencia, aunque necesaria, no es suficiente.

Una vía examinada abundantemente por Lacan tiene que ver con la literalidad del significante, con el sonido, con la letra. En el Seminario 5 (Lacan, 1998), retornando a lo que Freud descubre en torno al Witz ${ }^{3}$, muestra que lo central de esta formación no está sólo del lado de la significación, sino en el juego sobre el material verbal, sobre el significante. Mannoni (1980) examina esta cuestión, que prefiere llamar literalidad, para tratarla de espaldas al neopositivismo. Parte de la idea de que la significación, la comprensión que parafrasea un enunciado cualquiera, es en cierto sentido la destrucción de la literalidad. Y esto es particularmente fuerte en la poesía que, recordemos, para Lévi-Strauss, siguiendo la intuición de Rimbaud, es un paradigma de la eficacia simbólica, en tanto ella, la poesía, puede cambiar el mundo.

Mallarmé (1985) tenía una idea muy interesante sobre el lugar de la literalidad en la poesía. Pensaba que el poeta busca sus tesoros en la lengua, en el material verbal, en su literalidad, y debía arreglárselas secundariamente para que esto pareciera tener un sentido con el fin de que su juego pudiera ser aceptado. Notemos que el tesoro está en el juego con

3 El Witz es el objeto del libro de Freud mal traducido como "El Chiste y su relación con el inconsciente". Digo mal traducido porque en estricto rigor el Witz no es un chiste, no es un cuento jocoso que yo ya sé y le cuento a otro. El Witz es algo que surge en el ingenio. Tiene que ver más con la talla y el retruécano. Es la razón por la que se conserva el término en alemán. 
el sonido, la literalidad, y el sentido es secundario, una promesa. El efecto del poema no está en su significación sino en su literalidad, a condición de que prometa un sentido sin nunca entregarlo del todo. Esto parece esencial.

Mannoni (1980, p. 107) cita unos versos de Apollinaire que le gustan mucho:

\section{La masa en todas direcciones movía mezclando}

Sombras sin amor que se arrastraban por el suelo. ${ }^{4}$

La pregunta es: ¿por qué estos versos le gustan? Examina muchas posibilidades respecto a las resonancias que le trae el poema y también posibles lecturas: se trata de una masa de gente que se mezcla en una gran ciudad; cada uno está en medio de desconocidos y no puede no soñar, aunque sea confusamente, con un encuentro amoroso. Es lo que representan esas sombras que se arrastran y se mezclan por el suelo, sin amor, desafortunadamente, ya que la calle es el lugar de la promiscuidad y de la prostitución (Trainaient, está cerca de traînnée, que significa prostituta en el uso).

Por pertinente y acertado que sea el comentario, Mannoni (1980) estima que destruye el poema, destruye el efecto que tiene en él, como se destruye un enigma cuando se ha encontrado la palabra. Freud (1905) también, una vez establecido el sentido del Witz del "famillionario", señala que este no da cuenta del efecto del juego de palabras como tal, puesto que no produce la risa. Este efecto se debe a la literalidad del neologismo, a la condensación de los elementos verbales mismos.

Tampoco los análisis clásicos del arte poético son capaces de dar cuenta del efecto de la poesía. Mannoni (1980) comenta que la literalidad se impone, distanciándose por oscuros medios del riesgo de ser consumida por el sentido. No se sabe en verdad cómo la versificación produce el efecto poético. Avanzará un paso diciendo que el poema opera como una mueca. Se trata de una tesis de Jean-Martin Freud (el hijo de Freud) cuando tenía 9 años. El nińo recita unos versos que no son apreciados por su padre, quien le significa que tienen poco valor. Ante esto, el pequeño Martin

4 La foule en tous les sens remuait en mêlant

Des ombres sans amour qui se traînaient par terre. 
se excusa diciendo: "cuando hago versos así, es como hacer muecas" (en Mannoni, 1980, p. 111). Freud pudo haberse detenido a pensar esta frase, pero tomado por un cierto clasicismo respecto a la poesía no lo hace. ¿Qué puede implicar que la poesía sea una mueca? ¿Qué son las muecas?

Mannoni escribe:

"Las muecas son como expresiones fisiognómicas, pero que no están codificadas en tanto expresiones. La felicidad, la tristeza, el asco, la sorpresa, etc., son muecas codificadas, es decir expresiones que tienen un sentido. Son metabolizables en palabras -yo diría que en tal caso son la misma cosa que la prosa. Por el contrario, se llama muecas a algo que se asemeja a signos que no significan. Yo diría que no salen de su literalidad. Las muecas se parecen a las expresiones. Pero solo parecen tener un sentido. Pero esto se encuentra en otros lugares: los movimientos inútiles, sin significación, con pasos que no van a ninguna parte, están en el fundamento de la danza. El canto y la música utilizan posibilidades sonoras y vocales que no tienen significación... Seguramente hay en el material lingüístico posibilidades de combinación que no han recibido ninguna utilización codificada y con las cuales se puede jugar. Jean-Martin Freud puso tal vez el dedo en algo importante" (1980, p. 112).

El que Freud no lo haya entendido así, puede deberse a que tenía una relación muy particular con elementos sin significación. Por ejemplo, la música no era de su agrado, pues confesaba no poder apreciar un arte que no podía entender. Más aún datos biográficos, diversos, algunos aportados por el mismo Martín, indican que a Freud le desagradaba la música, rasgo extraño en un vienés (Cain \& Cain, 1982).

La idea de la poesía como mueca, como promesa de sentido, que se podría extender a la intervención analítica, es extremadamente interesante. Y para profundizarla, vale la pena examinar el interés y los límites de las teorías de la metáfora en el campo de la filosofía del lenguaje. Por ejemplo, Davidson (1993) sostendrá que la metáfora es un acto que opera como 
un bastonazo, lo que está cerca de la idea de la mueca. Propone que la teoría semántica de la metáfora, según la cual habría un sentido figurado (o segundo), al lado del sentido literal, tiene su origen en el interés por defender la capacidad que tendría la metáfora para decir la verdad.

Para la antigüedad clásica, una frase como "el espíritu de Dios volaba sobre el agua" era absurda literalmente y, por tanto, falsa. Pero todo se arreglaba si se consideraba "volar" en un sentido metafórico. Esto era tan evidente, por ejemplo, para San Agustín, que no se planteaba ningún problema a este respecto, y recomendaba vivamente conocer los "tropos" a quien quisiera estudiar las escrituras. De paso, observemos que para Freud el problema del sueño y del síntoma se plantea en los mismos términos: el texto del sueño es absurdo considerado literalmente, pero no lo es si se accede a su significación segunda, el sentido latente. Lo mismo respecto al síntoma histérico: la histérica no miente (como lo pensaban los neurólogos de la época, tomando literalmente el síntoma) sino que hay una verdad, histórica, o en todo caso psíquica, que se enuncia a través del síntoma. Es claro que se trata de una articulación semántica del problema.

Davidson (1993) pone el acento en la pragmática. La metáfora pertenece -según él- exclusivamente (he ahí su radicalidad) al dominio del uso. No existiría ningún sentido o significación particular de las expresiones metafóricas, ningún significado o contenido cognitivo implícito sugerido bajo el sentido literal, sino que realizarían su prodigio a través del puro sentido literal de las expresiones que forman. De nuevo al pasar, notemos que es esto lo que Freud señaló respecto a la simbolización en el síntoma histérico. Pero este aspecto de sus planteamientos fue muy olvidado y ha sido Lacan quien lo recuperó con fuerza. Para Freud (1895) expresiones como "golpe en el corazón" o "eso que me dices es como una bofetada en el rostro" son tomadas al pie de la letra en la histeria como si fuera un evento real, en particular en la conversión, dando lugar a malestares cardíacos o parálisis faciales, por ejemplo. Esto hacía decir a Freud que la histérica no se toma libertades con las palabras. Forester (1980) señala que en este estadio de la reflexión freudiana "el mecanismo de simbolización implica la puesta en acto del sentido literal de una expresión figurada" (p. 127). 
Algo similar dice Freud (1900) -también más marginalmente- respecto al sueño, al sostener que este tiene la estructura de un rebus, suerte de escritura iconográfica, el cual, más que ser interpretado, debe ser leído en su literalidad significante.

Pero volvamos a Davidson. Puesto que si tomamos las metáforas en su sentido literal, estas resultan ser falsas, absurdas, paradojales, contradictorias o imposibles. Habría que admitir que se trata de expresiones que no tienen por fin significar algo. No son ni aserciones ni proposiciones. Serían herramientas lingüísticas que, a través de su sentido literal, actúan sobre nuestra imaginación llamando nuestra atención, haciéndonos caer en la cuenta de algo, al modo que lo hace un bastonazo.

Tomemos un ejemplo. Alguien dice: "la ayuda económica al tercer mundo es una píldora anticonceptiva”. ${ }^{5}$ Literalmente esta frase es absurda y falsa. Solo al considerarla bajo el ángulo metafórico podría tener un sentido y podríamos pretender que dice alguna verdad. Justamente es esto lo que recusa Davidson (1993), proponiéndonos que lo que la metáfora realiza lo hace a través de su único sentido, el literal. Su efecto entonces se produce pragmáticamente y no semánticamente, como en el caso de las proposiciones. La imagen del bastonazo puede servirnos a entender mejor esto. El bastón está hecho para apoyarse y si yo le doy un bastonazo a alguien, hago un uso diferente del que está previsto. Hay algo no codificado, como en la definición de mueca de Mannoni (1980). Análogamente, cuando se enuncia una metáfora que se sabe que es falsa, se la enuncia, no para significar algo, sino para otra cosa, para realizar un acto, como el bastonazo.

Es necesario precisar que Davidson (1993) no niega que la metáfora pueda ser sugerente. Acepta como un lugar común el que produce una cierta concepción de su objeto, más que expresarlo directamente. Dice no tener nada que discutir con estas descripciones de los efectos de la metáfora, sino que critica la teoría sobre los modos a través de los cuales la metáfora produciría su efecto. No piensa que la metáfora realice su efecto a través de un significado especial que le sería propio ni por una suerte de contenido cognitivo específico implícito.

5 Tomo este ejemplo del comentario que el filósofo chileno Juan Rivano (1986) hace de las ideas de Davidson. 
Encuentra un argumento que apoya a su propuesta en el hecho ampliamente aceptado, incluyendo a Mannoni, como se mostró antes, de que es difícil, o incluso imposible, parafrasear una metáfora. Retomemos el ejemplo anterior. Alguien quiere decir que la ayuda económica al tercer mundo tiene como finalidad disminuir los riesgos de la explosión demográfica. En vez de decirlo así, utiliza la metáfora: "la ayuda al tercer mundo es una píldora anticonceptiva”. Para el que escucha esta frase sería difícil pretender que solo se alude a la explosión demográfica. Alguien podría entender que se hace referencia al interés de los países industrializados en mantener o reducir los niveles de industrialización del tercer mundo, captando así el aspecto de "esterilización del tercer mundo" que invoca la metáfora de la píldora. Y hay otras posibilidades. El locutor, entonces, debería reconocer que, más allá de sus intenciones, la metáfora dice más que la expresión literal de su pensamiento.

Tenemos, así, que algo es dicho para decir otra cosa, para sugerir con gracia o con ironía un pensamiento. Pero en el instante en que se enuncia la metáfora el pensamiento es sobrepasado, un exceso se produce y es muy difícil sostener que podríamos parafrasear literalmente lo que se ha dicho: el sentido metafórico se resiste a transformarse en sentido literal, o pensamiento teórico, como lo expone Mannoni (1980). Pero, sorpresivamente, Davidson concluye que esta dificultad de parafrasear no se debe a una gran riqueza de sentidos de la metáfora, sino a "que no hay nada que parafrasear" (1993, p. 351).

Ahora bien, no solo los teóricos de la pragmática se oponen a la posibilidad de traducción o paráfrasis de la metáfora. También algunos defensores de la teoría semántica lo hacen. Para Ricoeur (1997), por ejemplo, una teoría semántica es una investigación sobre la capacidad de la metáfora para entregar información intraducible y, por lo tanto, sobre la capacidad de la metáfora para ofrecer un conocimiento profundo y verdadero de la realidad. Entonces, si Davidson acepta caracterizar los efectos de la metáfora como su capacidad de producir o sugerir una cierta visión de su objeto, más que de decirlo explícitamente, ¿por qué no acepta dar el nombre de significaciones a tales efectos? ¿Se trata de una mera querella terminológica? Davidson se opone porque piensa que tras la teoría semántica hay otra teoría, según la cual la metáfora contiene un elemento cognitivo que solo ella podría 
transmitir y el cual debería ser captado para comprender la metáfora. Dice entonces que "para explicar cómo las palabras funcionan en las metáforas, no sirve de nada postular significaciones metafóricas o figurativas de un tipo especial. Estas nociones no explican la metáfora, es más bien la metáfora que las explica” (1993, p. 352). Esto es muy cercano a la idea de Mannoni (1980) según la cual la paráfrasis destruye la poesía o es una defensa contra ella.

\section{Conclusión}

El recorrido que hemos seguido indica que la eficacia simbólica en Lévi-Strauss -que marcó radicalmente el pensamiento psicoanalítico desde Lacan hasta nuestros días en lo que a la concepción de la cura se refiere- junto con sugerir permanentemente la dimensión pragmática de la palabra en la cura, la yerra. Para Lévi-Strauss (1958) es claro que los actos pueden ser un lenguaje, pero es menos claro que la palabra sea un acto. Con todo, a partir de una definición formal de la "eficacia simbólica", como propiedad inductora entre estructuras formalmente homólogas, ubica la poesía como paradigma de este proceso, donde el cambio es lo central y no la comprensión. Esta indicación se sigue trabajando en torno al modelo de la metáfora, como paradigma de cómo entender la intervención (interpretación) psicoanalítica. Las indicaciones de Lacan (1998) sobre el Witz y las de Mannoni (1980) sobre la versificación como una "mueca", parecen responder a la misma intuición de Davidson (1993) que considera la metáfora como un bastonazo, como un uso de lenguaje que produce su efecto a través de su literalidad y no a través de su sentido simbólico o segundo. Esto sugiere que la "eficacia simbólica" puede ser revisitada desde el punto de vista pragmático, lo que nos daría otra perspectiva sobre la interpretación psicoanalítica, y de manera más general, sobre el problema de porqué las palabras curan. ¿Significa esto que la semántica (el sentido) es una ilusión a sobrepasar con la pragmática?

Si siguiéramos radicalmente la teoría de Davidson (1993), darían lo mismo las palabras usadas en la metáfora o, por extensión, en la intervención analítica. Incluso podríamos llegar al extremo de pensar que podemos intervenir en otra lengua. O como lo dice Mannoni (1980), podríamos leer poemas en una lengua que nos es desconocida, si todo lo que es determinante 
en el efecto es la literalidad. Pero aquí de nuevo son los poetas, más que los filósofos, quienes orientan la reflexión analítica. Recordemos que para Mallarmé (1985), junto con el juego de lenguaje, la poesía debe prometer como horizonte un sentido. $Y$ es que en poesía, como en la intervención analítica, esa promesa de sentido, tal vez incierta y errática, es muy importante para la eficacia. El efecto analítico tiene que ver con una promesa de dar un sentido sin darlo nunca completamente. Se trata de una promesa no cumplida, pues es imposible, pero sin tal promesa no hay eficacia simbólica.

Veamos esto en el Witz. Este requiere de la risa del otro para realizarse. Sin risa, no hay Witz. Se trata claramente de un efecto pragmático. Pero ¿podríamos decir con Davidson que basta la risa para que se realice el Witz? Pareciera que si el otro se ríe para no develar que no ha entendido la talla, por vergüenza de parecer tonto, por ejemplo, y se percibe la impostura de su risa, no hay realización del Witz (ni del deseo), ya que no hay satisfacción. El otro no es un verdadero cómplice de mi deseo si ríe sin comprender nada. Otra cosa es que esta comprensión no baste para dar cuenta del efecto del Witz, y que lo que hace reír esté más allá de lo comprendido, como algo siempre incomprendido, como lo plantea Lacan (1998). Pero lo importante es que se opera la promesa de sentido, suerte de ilusión estética, decisiva para la producción del acto, el efecto pragmático. De aquí se deriva el interés de la proposición de Lacan de ejercer la intervención analítica más como una poética que como una explicación. No se trata de banalizar el diálogo clínico reduciéndolo a un mero juego de palabras, sino de hacer emerger las promesas de sentido necesarias, las que luego se tornarán caducas con la "liquidación de la transferencia" (Freud) o su "caída" (Lacan).

El nivel lógico-semántico y el pragmático se requieren mutuamente para constituir el efecto, pero la teoría puede distinguirlos. Es en este punto donde el psicoanálisis se demarca de la filosofía analítica, ya que introduce una finalidad al "juego de lenguaje". Para Wittgenstein (1985), el juego de lenguaje es autónomo, porque a diferencia de otras prácticas, no se define por sus fines; no es un arreglo de palabras destinado a cumplir un fin determinado. Es decir, que Wittgenstein (1985) evacúa la cuestión del referencial, externo o interno. Y por el contrario, para Freud, el juego de lenguaje gravita en torno a un referencial, el inconsciente, sobre el que la metapsicología debe continuar haciendo la teoría. 


\section{Referencias}

Adam, J. M. (1990). Aspects du récit en anthropologie. En J. M. Adam, M-J. Borel, C. Calame, M. Kilani. Le discours Anthropologique (pp. 251-282). Paris: Méridiens Klincksieck.

Augé, M. (1979). Symbole, Fonction, Histoire: les interrogations de l'anthropologie. Paris: Hachette.

Austin, J. L. (1962). Performatif-Constatif. En Cahiers de Royaumont. La philosophie analytique (pp. 271-304). Paris: Minuit.

Badiou, A. (2000). Acto analítico, acto político, acto poético. Revista Asociación Escuela Argentina de Psicoterapia para Graduados, 26, 249-270.

Benveniste, E. (1967). Problèmes de linguistique générale, Paris. Gallimard. Bourdieu, P. (1982). Ce que parler veut dire. Paris: Fayard.

Cain, J. \& Cain, A. (1982). Freud, absolument pas musicien. En J. Cain \& G. Rosolato. Psychanalyse et Musique (pp. 91-137). Paris : Ed. Les belles lettres.

Davidson, D. (1993). Enquêtes sur la vérité et l'interpretation. Nîmes: Ed. Jacqueline Chambon.

Forester, J. (1980). Le langage aux origines de la Psychanalyse. Paris: Gallimard.

Freud, S. (1997). Estudios sobre la Histeria. En: Obras Completas, vol. II, B. Aires: Amorrortu.

Freud, S. (1997). El chiste y su relación con el inconsciente. En: Obras Completas, vol.VIII, B. Aires: Amorrortu.

Freud, S. (1997). La interpretación de los sueños. En: Obras Completas, vol.V, B. Aires: Amorrortu.

García, M. (2000). La perte et le deuil déguisés en possession: considérations ethnopsychanalytiques sur la maladie du susto au Chili. En D. Weil(Ed.) Mélancolie: au delà des versions singulières et culturelles de la dépression (pp.141-166), Strasbourg: Presses Universitaires de Strasbourg.

García, M. (2001). Psicoanálisis del mal: el discurso de la brujería como tratamiento cultural del Narcisismo, Gradiva, 2, 173-188.

Jakobson, R. (1963). Essais de linguistique générale. Paris: Ed. Du Minuit.

Lacan, J. (1998). Le séminaire, Livre V. Les Formations de l'inconscient. Paris: Seuil.

Lacan, J. (2001). L'acte psychanalytique. Séminaire 1967-1968. Paris: Editions de l'Association Freudienne Internationale (publicación interna).

Lévi-Strauss, C. (1958). L'efficacité symbolique. En Anthropologie Structurale, (pp.205-226) Paris: Plon.

Lipovetsky, G. (1983). L ère du vide: essais surl'individualisme contemporain. Paris: Gallimard. 
Mallarmé, S. (1985). Correspondance, vol.9, Paris: Gallimard.

Malinowsky, B. (1974). Les jardins de corail, Paris: Maspero.

Mannoni, O. (1980). La littéralité. En: Un commencement qui n'en finit pas, Paris: Seuil.

Mannoni, O. (1987). Le divan de Procuste. En J. Mc Dougall, O. Mannoni, D. Vasse \& L. Dethiville. Le divan de Procuste (pp. 1546). Paris: Denoël.

Ricoeur, P. (1997). La métaphore vivante. Paris: Seuil.

Rivano, J. (1986). Perspectivas sobre la metáfora. Santiago de Chile: Editorial Universitaria.

Searle, J. R. (1987). Speech acts: An essay in the philosophy of language. Cambridge: Cambridge University Press.

Strachey, J. (1934). The nature of therapeutic action of psycho-analysis, International Journal of Psycho-analysis, 15, 127-159.

Wittgenstein, L. (1985). Etudes préparatoires à la seconde partie des recherches philosophiques. Mauvezin: Trans-Europ-Repress.

Zweig, S. (1935). La guérison par l'esprit. Paris: Stock.

Fecha de recepción: 25 de agosto de 2010.

Fecha de aceptación: 03 de junio de 2011. 